\title{
Doping Prevention in Sport: Overview of Anti-Doping Education Programs
}

\author{
Beatričè Sipavičiūtė, Saulius Šukys, Audronė Dumčienė \\ Lithuanian Sports University, Kaunas, Lithuania
}

\begin{abstract}
Background. As doping can damage the sports industry, it is fundamental for athletes to engage in the anti-doping education programs and understand the anti-doping rules. The purpose of this article was to provide an overview of research focusing on anti-doping education.

Methods. Scientific research analysis was done by focusing on doping prevention and education programs.

Results. Anti-doping education should focus on young athletes, involve family members, friends and coaches. In relation with anti-doping programs which concentrated on health education and informative knowledge, moral and ethical behaviour based anti-doping education was believed to be more effective in actual doping behaviour of athletes. Since coaches could be potentially influencing athletes' doping behaviour, there should be a collaboration of sports organizations and policy makers in order to help coaches operate within anti-doping rules by creating certain doping prevention programs.

Conclusions. Research studies which examine athletes' belief system and provoke critical thinking in athletes about using banned substances in sport might be more effective in preventing doping than programs focusing only on health education.
\end{abstract}

Keywords: anti-doping, doping, education, prohibited substances.

\section{INTRODUCTION}

$\mathrm{T}$ The world's second fastest man, Tyson Gay, had to return the silver medal he won in 2012 London Olympic Games after he was tested positive in anabolic steroid test. Doping can bring shame on athlete's reputation and people will always doubt about the actual abilities of athletes who used doping in the past even if they declare they are clean in the present.

Doping itself is a dangerous threat to athletes worldwide. It damages the principle of fair competition in sport (Triviňo, 2011), intimidates the practice of sport and puts athletes under pressure. Furthermore, it has a harmful effect on the image of the sports industry and can cause a serious harm to athletes' health condition (Mazzeo et al., 2018). Doping may lead to reduced athlete's fertility, disturbed mental health or hypertension (Bird, Goebel, Burke, \& Greaves, 2016). Doping is the use of illegal performance enhancement substance by athletes to improve their abilities in sport (Vorstenbosch, 2010). Over the years, medical field progressed to the point where even using human genes became a tool for fraudulent athletes' behaviour (Fischetto \& Bermon, 2013), in other words, the use of genes as a new form of doping (Baoutina, Coldham, Fuller, \& Emslie, 2013).

The use of banned drugs in sport involves the need to improve results and strive to control methods by which enhancement could be achieved (Petróczi, Norman, \& Brueckner, 2017). Doping can be defined as variety of prohibited drugs used by athletes and illegal methods that improve sport results (Murofushi, Kawata, Kamimura, Hirosawa, \& Shibata, 2018). Thus, doping is illegal because of the fact that it gives athletes an unfair advantage over their opponents (Johnson, 2012). 
From legal point of view, doping in sport is controlled by the World Anti-Doping Code(WADA, 2015). Any implementation activities of the Code are supervised by the World Anti-Doping Agency (Petróczi, Norman, \& Brueckner, 2017). The World Anti-Doping Agency (WADA) was created in order to protect all athletes from doping. The main aim of this agency is to ensure a drug-free sport and effective anti-doping educational programs to prevent doping (ADO Reference Guide, 2015).

Though it is questioned whether all sports can be "clean" from the use of prohibited drugs (Dimeo, 2016), it is important to protect health and basic rights of athletes as it is stated in World AntiDoping Code and to promote fair competition. The anti-doping preventive education programs and understanding of anti-doping rules is required for all athletes regardless of whether they compete at the national or international level (Murofushi et al., 2018). It is crucial to develop modern educational tools that are suitable for the next generation of athletes which could allow them to engage and learn about drug free sport effectively (Barkoukis et al., 2019).

\section{METHODS}

Since research analysis on anti-doping education programs during the last years has increased (Codella, Glad, Luzi, \& La Torre, 2019; Barkoukis et al., 2019), it is worth to have more analysis of such studies. The purpose of this article was to provide an overview of research focusing on anti-doping education programs. Specifically, the purpose of this study was not to make a comprehensive analysis of all previous publications, but focus on the analysis of empirical studies which provide concrete for anti-doping programs. Therefore, the article starts by analysing the concept of doping prevention and education. Then we examine anti-doping education programs. Further we propose practical recommendations and future research directions.

\section{RESULTS AND DISCUSSION}

The concept of education for doping prevention. In order to achieve doping prevention, doping tests are not sufficient because a change in athletes' attitudes is needed. After all, there is a chance that drug testing alone could fail, as it was seen in the various cases, e.g. a doping incident involving Lance Armstrong. Therefore, anti-doping education may be the only way to reduce doping culture in sport.

There is a great need to establish attitudes towards doping at an early point in athletes' careers (Lentillon-Kaestner, Hagger, \& Hardcastle, 2012). Relationships between coaches and family members could decrease or increase the athletes' behaviour towards the use of illegal drugs (Dunn, Thomas, Swift \& Burns, 2012). The intention to engage in doping could be reduced by changing positive attitudes towards doping into negative, and teaching to refuse taking illegal drugs under pressure (Lazuras, Barkoukis, Rodafinos, \& Tzorbatzoudis, 2010). Moreover, educational courses with discussions related to doping could be particularly welcome for coaches and athletes (Striegel, Ulrich, \& Simon, 2010). The research shows that elite athletes need education strategies which could help them make informed decisions on the properties of medications for performance enhancing purpose (Mottram, Chester, Atkinson, \& Goode, 2008). Athletes' knowledge about doping could be improved by using website platforms with updated lists of acceptable supplements and medicines (Striegel, Vollkommer, \& Dickhuth, 2002). These researchers suggest that internet resources which allow accessing information on illegal substances in sport should be promoted. Lucidi et al. (2017) point out that media literacy intervention could be effective in changing students' views of doping substances and PAES (Performance and Appearance Enhancing Substances). Such intervention also seemed to reduce students' selfreported use of PAES.

Also, it must be mentioned that regarding age differences, individual consultations on dietary supplement use may be better use for older athletes, while presentations given by professionals of sport science may be a more appropriate educational strategy for younger athletes (Erdman, Fung, DoyleBaker, Verhoef, \& Reimer 2007). Gender differences should also be taken into account within educational strategies. The research shows that the athletes' coaches, family and friends could also benefit from participating in anti-doping education programs, especially in relation to possible risks of illegal drugs use and anti-doping laws (Nieper, 2005).

There are a few studies which have examined the effectiveness of anti-doping education programs. Most of the preventive educational programs which focus on the use of illegal drugs in 
sport are ineffective because informing athletes of possible health risks does not reduce the use of banned substances (Peters, Schulz, Oberhoffer, \& Michna, 2009).

In study conducted by Hallward \& Duncan (2019), young adult athletes were interviewed about doping education. Most of the athletes who participated in this study expressed a lack of doping education. Some athletes said that doping was mentioned only briefly by psychical educator or coach. Athletes who played volleyball or badminton thought anti-doping education was not relevant. Only few athletes recalled adequate education of doping prevention. These athletes competed in national or higher level in sport. Most of athletes agreed that anti-doping education should involve not only athletes but also parents, trainers, coaches and doctors. Athletes expressed the need for short and frequent educational programs. Also, athletes suggested using scare-based method which would discourage athletes from illegal substances. However, some researchers suggest that doping preventive programs which focus on young athletes should not highlight the negative effects of doping due to the fact that athletes seem to understand the possible harmful consequences related to doping already very well (Peretti-Watel et al., 2005).

In a qualitative study which involved athletes and coaches in Greece and Australia, Barkoukis, Brooke, Ntoumanis, Smith, and Gucciadi, (2019) revealed what factors most likely influenced athletes' attitudes to avoid doping. Five main factors were identified: peer influence, coach influence, doping stigma, doping stance, and environmental culture. The results of the study revealed that the attitudes of most athletes were strictly anti-doping, however athletes could not explain their position. Probably due to the stigma of doping and not because they lacked anti-doping education. The main factor influencing anti-doping attitude was the anti-doping culture in athletes' environment. It must be concluded that doping education should include not only athletes, coaches, but also wider environment of athletes.

There are some opinions (Chan et al., 2020) that athletes may use unintentional doping. A systematic analysis of studies related to the unintentional consume of illicit drugs (Chan et al., 2020) has shown that doping can be determined by a relatively wide range of behavioural and social psychological factors, as well as willpower characteristics. The results of this study revealed that changing attitudes and intentions to use banned drugs requires athlete training methods and tools that influence a person's behaviour developing his or her willpower characteristics, and his or her social psychological environment.

All things considered, such institutions as national and international anti-doping agencies and sports federations should invest a lot more money to doping prevention programs because in some cases sports institutions start doping educational programs with no proper monetary investment (Morente-Sánchez \& Zabala, 2013). That is to say, anti-doping education could include a wider athlete's environment, coaches, parents, and friends to be more effective in reducing doping.

The evaluation of anti-doping education programs. Doping prevention programs targeting health education. Anti-doping education programs, which concentrate on health education and help to gain knowledge about doping prevention are quite common in research world (Melzer, Elbe, \& Brand, 2010).

Anti-doping programs, conducted in early 2000s, include ALTAS and ATHENA, which mainly focused on young athletes (Elliot et al., 2004; Goldberg et al., 2000). These doping prevention programs concentrated on such factors as attitudes towards doping, knowledge about doping, and intention to dope. Furthermore, both ALTAS and ATHENA consisted of topics related to healthy diet and alternatives to doping. Results point out that these doping prevention programs were effective in decreasing the possibility to use banned substances, reducing interest in illegal drugs, and providing knowledge of alternatives to doping (Elliot et al., 2006).

ATHENA and ATLAS educational programs present problems related to alcohol and tobacco consumption, unhealthy eating habits and the use of illegal drugs in sport. However, it should be kept in mind that the ATHENA and the ALTAS educational anti-doping programs were developed 20 years ago, so the main ideas of these programs did not incorporate the results and developments of the last two decades (Barkoukis, Kartali, Lazuras, \& Tsorbatzoudis, 2016). Despite the fact that both ATLAS and ATHENA had impact on reducing the intention to use prohibited substances in sport, they had little effect on actual behaviour and doping use (Ntoumanis Ng, Barkoukis, \& Backhouse, 2014).

More recent studies related to knowledgebased anti-doping education include HERCULES 
program (Sagoe et al., 2016). HERCULES education program is based on the combination of practical strength exercises and theoretical knowledge. The effectiveness of the intervention was examined on high school students (age: 15-21). Students were randomly assigned to theory only group, theory with strength training or control group. Practical training was done in the form of strength training exercises and lasted for twelve weeks. At baseline and after the intervention students completed a questionnaire about self-rated physical strength, anabolic-androgenic steroid use and intention to use steroids, anti-doping knowledge, alcohol use, tobacco use, nutrition behaviour, strength training self-efficacy, attitude towards drugs offers, muscle appearance satisfaction, and attitude towards doping. Results show that theory and strength training group score higher on muscle appearance satisfaction and strength training self-efficacy than theory only group. Also, strength training group gain more knowledge about steroid harm on health than control group. Therefore, the combination of theoretical knowledge and effectiveness of strength training exercises can be helpful in preventing doping.

Recent anti-doping programs targeting heath education include ALPHA program (Murofushi et al., 2018), which highlighted that athletes who were educated about doping prevention at least once, had a higher level of knowledge in comparison with others, that is to say, in order to improve athletes' knowledge of anti-doping, athletes should be educated more than once. Other interventions, such as "Lotta al Doping" (Codella, Glad, Luzi, \& La Torre, 2019) were also effective in increasing athletes' knowledge about doping.

The limited impact of anti-doping education programs which are based on knowledge about doping and damage to health, was demonstrated by a long-term study conducted in elite sports schools in Germany by Wippert and Fließer (2016). In Germany, the National Doping Prevention Plan (NDPP) was introduced with two main objectives: structural change in the field of doping prevention and the development of doping prevention education measures for young athletes. The results of the four-year study showed only partial confirmation of NDPP expectations. The impact of the NDPP has changed the content of doping prevention, but not the transformation of the structure (frequency, type, and scope) of anti-doping education in elite sports schools. Students of elite sports schools who were covered by the NDPP education program at the anti-doping knowledge test showed that they had significantly more knowledge than those in the control group, however the difference was very small and may not become a real basis for behaviour change.

In order to establish the importance of knowledge about doping, the study by Horcajo, Santos, Guyer, \& Moreno (2019) examined the influence of the individual need of cognition impact on the attitudes and future intentions of Spanish athletes to use banned drugs and attitudes to the legalization of doping. Anti-legalization information was sent to some subjects and pro-legalization information was sent to the rest of the subjects. The results of the study showed that the subjects who received information against the legalization had significantly less favourable attitudes towards the legalization of the use of prohibited drugs than those who received the information supporting the legalization. Personal need of cognition moderated the relationship between athletes' approaches to doping and their intentions to use doping in the future. In addition, athletes with a high need of cognition expressed their views and intentions to doping much more strongly. This shows that education influences athletes' attitudes towards the use of banned drugs and their intentions in the future. However, the study did not reveal how to change attitudes and intentions regarding the use of illicit drugs. Although knowledge of the attitudes of athletes and coaches towards the use of illicit drugs is very important for the prevention of doping, there are very few studies analysing the possibilities for changing attitudes to doping, according to the study authors.

The results of a study conducted by Hurst, Kavussan, Boardley, and Ring (2019) showed that athletes who believed only that dietary supplements were effective in achieving high results were more likely to use prohibited drugs as well. Therefore, anti-doping education programs should address the beliefs of athletes about the effectiveness of dietary supplements.

Athletes college students were asked (Ring, Kavussanu, \& Gürpınar, 2020) to evaluate their basic values, moral disengagement, and anticipated guilt in hypothetical situations. The results showed that athletes' values were directly (selfenhancement) and indirectly (self-transcendence, conservation) related to the probable use of banned drugs and cheating in sport. Thus, the development of basic values as main guidelines for life in antidoping education programs should be one of the key factors, emphasizing moral and ethical aspects. 
That is to say, knowledge-based education programs which target health damage might not be the most effective education tools in minimizing real life doping use.

Doping prevention programs targeting moral and ethical education. Many anti-doping education programs, such as proposed by Goldberg et al. (2000) or Laure and Lecerf (2002), are focused on health education and target transferring important knowledge about doping on athlete that one may decrease the intention to dope and change attitude towards doping (Melzer et al., 2010). Nonetheless, the effectiveness of such knowledge-based educational doping prevention programs is low (Laure \& Lecerf, 2002). It may be unsatisfactory to only concentrate on teaching knowledge about doping in sport (Hanson, 2009) because other approaches on anti-doping education must be incorporated. Doping in sport could be related to moral factors, specifically moral identity. Moral identity is based on Bandura's (1991) social cognitive model of moral behaviour and could be described as "a self-conception organized around a set of moral traits" (Aquino \& Reed, 2002, p. 1424). Researchers highlighted that people differed in the degree to which they thought being a moral or good person, the main part of their self-concept (Aquino \& Reed, 2002). Generally, the source of motivation to behave morally is moral identity. Notably, it was found that athletes who were positive about cheating in sport had low morale (Gucciardi, Jalleh, \& Donovan, 2011; Nicholls et al., 2015). Therefore, recent studies confirmed that doping was associated with moral identity (Kavussanu, Ring \& Hurst, 2018). Athletes who thought that being moral was important to their self-concept were less likely to use illegal drugs in sport (Kavussanu \& Ring, 2017). This study also found that association between doping and moral identity could be mediated by anticipated guilt. Therefore, athletes with a strong moral identity might avoid using illegal drugs because they would expect to feel intense guilt. Other studies (Corrion, Scoffier-Meriaux, \& d'Arripe-Longueville, 2017) discovered that personal ability as a temptation to use performance enhancement drugs was also a meaningful factor.

More promising scientific interventions might be which are created to examine the validity of athletes' belief system and provoke critical thinking about using illegal drugs in sport (Melzer et al., 2010). Generally, athletes gain common knowledge about doping prevention in sport, however knowledge itself might be difficult to apply when a real-life situation occurs.

The improvement of anti-doping education includes evaluation on a regular basis as many doping prevention programs are organized with no reports of theoretical background, effects and results (Hanson, 2009). In addition to evaluation on regular basis, anti-doping education should focus on by now existing knowledge of athletes (Hanson, 2009) because knowledge about doping in sport could change during the whole athlete's life (Melzer et al., 2010).

More frequently used dependent variables are attitude towards doping, knowledge about doping, and intention to dope (Melzer at al., 2010). However, these factors do not explain actual doping behaviour effectively (Backhouse, McKenna, Robinson, \& Atkin, 2007). The theory of planned behaviour (Ajzen, 1985) is a common model in order to explain doping in sport. Notwithstanding, some researches think that doping is not a planned action (Melzer et al., 2010). The decision to use illegal drugs in sport is also described as cognitive processes which is weakly evaluated and spontaneous action (Petróczi, Aidman, \& Nepusz, 2008).

Therefore, WADA is stepping up its efforts to enhance the role of values in anti-doping education programs. In 2017, WADA established a working group that prepared recommendations for priority value-based anti-doping education programs for athletes. These educational programs are based on moral and ethical vualues. Houlihan, Downward, Yamamoto, Rasciute, and Takasu (2020) conducted a large-scale study of public opinion in the United Kingdom and Japan to assess the importance of the "sports spirit" as a universal moral value and the significance of cultural values in accordance with the WADA Code. The aim was to contribute to the development of value-based anti-doping education programs. The results of the study showed that the development of anti-doping educational programs should be based not only on moral and ethical values, but also on the cultural environment, gender and age of athletes. Considering, anti-doping education programs which are based on health promotion, show little effect, there is strong urge to include ethical decision-making into cognitive structures (Melzer et al., 2010).

Coaches' role in anti-doping education. For the most part, coaches have been pointed out as potentially influencing athletes to be involved into 
doping behaviour. It is not surprising that research analyses the influence of coaches in relation to doping because coaches have importance and closeness to athletes (Goulet, Valois, Buist, \& Cote, 2010). Despite the fact that coaches are aware they have a serious responsibility to prevent athletes from engaging in doping (Laure, Thouvenin, \& Lecerf, 2001; Fung \& Yuan, 2006), they also might encourage the athletes to use illegal drugs (Laure et al., 2001). Research provides information that elite athletes view coaches as knowledgeable and inspirational figures and obey their authority without question (Smith et al., 2010). For this reason, it is quite predictable to see coaches being involved in various doping scandals, such as BALCO and Lance Armstrong cases (Patterson, Backhouse, \& Duffy, 2016). The possible impact of a coach on the athlete's doping behaviours could be explained by 'maladaptive behaviour' as doping may be influenced by coaches encouraging athletes to win at all costs (Barkoukis, Lazuras, Tsorbatzoudis, \& Rodafinos, 2011). Coaches' relationship with athletes and moral climate created by coaches could influence factors related with morality among athletes (Gonclaves, Coelho e Silva, Cruz, Torregrosa, \& Cumming, 2010; Steinfeldt, Rutkowski, Vaughan \& Steinfeldt, 2011). Moreover, coaches might have an impact on athletes' moral disengagement (Lucidi et al., 2008) and moral reasoning (O'Donnell, Mazanov, $\&$ Huybers, 2006) in relation to doping. Therefore, the possible influence of coaches towards doping behaviour is seen in anti-doping rules.

Legally speaking, coaches are referred as athlete support personnel, as it is stated in the World AntiDoping Code, which clearly highlights that coaches should counsel and educate athletes in relation to anti-doping rules and use their authority on athlete values to encourage anti-doping attitudes (WADA, 2015). Therefore, the Code stresses out that if coaches violate anti-doping rules by encouraging athletes to use banned substances or covering up the use such drugs, they can also be a subject to legal sanctions.

For this reason, WADA created The Coach's Tool Kit in 2007 in order to help coaches fulfil the anti-doping role, which provides useful material about anti-doping. Some researchers suggest using logic model for anti-doping education in relation to coaches (Backhouse, McKenna, \& Patterson, 2009; Houlihan \& Melville, 2011) because by using the logic model, doping prevention programs would be systematically justified and theoretically grounded and this could add to improvement of these programs.

Anti-doping rules make the coaches aware of their important responsibilities for doping prevention and education (Patterson, Duffy, \& Backhouse, 2014). After all, coaches provide information about doping to athletes (Laure et al., 2001; Backhouse \& McKenna, 2012). Both anti-doping organizations and policy makers should collaborate in order to create doping prevention programs which would help to operate coaches within anti-doping rules. Moreover, scientific research about anti-doping education in relation to coaches is needed, as researches analyses the potential influence of coaches to engage in doping behaviour.

A review of articles on anti-doping education has revealed that the problem of doping education and prevention is studied relatively widely and in various ways. The content of educational programs is mostly dominated by knowledge about health effects of doping and much less by moral and ethical aspects. The studies usually aim to find how much the subjects' knowledge increased after the intervention of the anti-doping education program compared to the control group that did not participate in the program. There are significantly fewer studies in which the aspect of anti-doping education programs predominates, emphasizing basic, moral, and ethical values. Researchers rarely look for methods and tools to change athletes 'attitudes toward the use of illegal drugs and their intentions to use such drugs in the future.

Key issues and future directions. Analysis of the scientific literature has revealed that in recent years more research has been done on antidoping education. Though there is a lot of scientific literature that analyse the concept of doping, there is also a growing number of studies that focus on anti-doping education programs. In this article we tried to review the concept of doping prevention and education and analyse effects of anti-doping education programs.

It has been found that anti-doping education programs provide useful information for athletes about doping and banned substances (Elliot et al., 2006). Doping education and prevention should target young athletes, involve family members, friends and most import coaches (Nieper, 2005).

Research showed the importance of antidoping education which targets moral and ethical behaviour. It was pointed out that although 
knowledge-based educational programs, such as ATHENA and ALTAS, were found to be effective in providing knowledge of alternatives to doping and reducing interest in illegal drugs, such programs had little effect in affecting actual doping behaviour of athletes.

When looking deeper into anti-doping education programs, their connection with athletes' intention to use prohibited substances, researchers revealed the possible relationship between coaches and athletes' intention to engage in doping behaviour. Importance and closeness of coaches, viewing coaches as knowledgeable and inspirational figures might have an impact on athletes' intentions to dope. Therefore, anti-doping rules and policy highlight their serious responsibilities for doping prevention and education in athletes. We hope that this overview might be an impulse for new research in Lithuania. Nowadays, there is lack of studies focusing on the effects of anti-doping educational programs.

\section{CONCLUSIONS}

To minimize the doping in sport, it is fundamental for athletes to engage in prevention and education programs which provide useful information about doping, starting with young athletes, involving family members, friends and coaches.

Though most doping prevention and education programs are concentrated on health education and providing informative knowledge about doping which could change athletes' attitudes towards doping and minimize their intention to dope, they doubly show any effect in actual behaviours. More promising research studies might be which examine the validity of athletes' belief system and provoke critical thinking in athletes about using illegal drugs in sport.

Since coaches could be potentially influencing athletes to be involved into doping behavior, there is a strong need for collaboration of sport organizations and policy makers in order to create doping prevention programs which would help to operate coaches within anti-doping rules.

Further research about anti-doping education programs should focus on the development of values in athletes, especially young athletes, and include their coaches and other persons close to them, and seek ways to change athletes' attitudes and intentions to use such drugs in the future with the help of educational programs.

\section{REFERENCES}

Ajzen, I. (1985). From intentions to actions: A theory of planned behavior. In Action control (pp. 11-39). Berlin, Heidelberg: Springer.

Aquino, K., \& Reed, A. (2002). The self-importance moral identity. Journal of Personality and Social Psychology, 83(6), 1423-1440. https://psycnet.apa.org/ doi/10.1037/0022-3514.83.6.1423

Backhouse, S., McKenna, J., \& Patterson, L. (2009). Prevention through education: A review of current international social science literature. A focus on the prevention of bullying, tobacco, alcohol and social drug use in children, adolescents and young adults. World Ant-Doping Agency.

Backhouse, S. H., \& McKenna, J. (2012). Reviewing coaches' knowledge, attitudes and beliefs regarding doping in sport. International Journal of Sports Science \& Coaching, 7(1), 167-175. https://doi. org/10.1260\%2F1747-9541.7.1.167

Backhouse, S., McKenna, J., Robinson, S., \& Atkin, A. (2007). Attitudes, behaviours, knowledge and educationdrugs in sport: Past, present and future (pp. 1-199). World Anti-Doping Agency.

Bandura, A. (1991). Social cognitive theory of moral thought and action. In W. M. Kurtines, J. L. Gewirtz (Eds.), Handbook of Moral Behavior and Development:
Theory, Research, and Applications (Vol. 1, pp. 45-103). Hillsdale, NJ: Lawrence Erlbaum Associates.

Baoutina, A., Coldham, T., Fuller, B., \& Emslie, K. R. (2013). Improved detection of transgene and nonviral vectors in blood. Human Gene Therapy Methods, 24(6), 345-354. https://doi.org/10.1089/hgtb.2013.128

Barkoukis, V., Brooke, L., Ntoumanis, N., Smith, B., \& Gucciadi, D. F. (2019). The role of the athletes' entourage on attitudes to doping. Journal of Sports Sciences, 37(21), 2483-2491. doi: 10.1080/02640414.2019.1643648

Barkoukis, V., Kartali, K., Lazuras, L., \& Tsorbatzoudis, H. (2016). Evaluation of an anti-doping intervention for adolescents: Findings from a schoolbased study. Sport Management Review, 19(1), 23-34. https://doi.org/10.1016/j.smr.2015.12.003

Barkoukis, V., Lazuras, L., Tsorbatzoudis, H., \& Rodafinos, A. (2011). Motivational and sports personship profiles of elite athletes in relation to doping behavior. Psychology of Sport \& Exercise, 12(3), 205-212. https:// doi.org/10.1016/j.psychsport.2010.10.003

Barkoukis, V., Tsiatsos, T., Politopoulos, N., Stylianidis, P., Ziagkas, E., Lazuras, L., \& Ypsilanti, A. (2019). A Serious Game Approach in Anti-Doping Education: The Game Project. In Proceedings of the 15th International Scientific Conference "eLearning 
and Software for Education": New technology and redesigning learning spaces, 3, 451-455.

Bird, S. R., Goebel, C., Burke, L. M., \& Greaves, R. F. (2016). Doping in sport and exercise: anabolic, ergogenic, health and clinical issues. Annals of Clinical Biochemistry, 53(2), 196-221. https://doi. org/10.1177\%2F0004563215609952

Chan, D. K. C., Tang, T. C., Gucciardi, D. F., Ntoumanis, N., Dimmock, J. A., Donovan, R. J., ... \& Hagger, M. S. (2020). Psychological and behavioural factors of unintentional doping: A preliminary systematic review. International Journal of Sport and Exercise Psychology, 18(3), 273-295. https://doi.org/10.1080/16 12197X.2018.1450095

Codella, R., Glad, B., Luzi, L., \& La Torre, A. (2019). An Italian campaign to promote anti-doping culture in highschool students. Frontiers in Psychology, 10(534), 1-5. https://doi.org/10.3389/fpsyg.2019.00534

Corrion, K., Scoffier-Meriaux, S., \& d'ArripeLongueville, F. (2017). Self-regulatory mechanisms of doping intentions in elite athletes: The role of self-determined motivation in sport. Journal of Sports Medicine \& Doping Studies, 7(4), 197. doi: 10.4172/2161-0673.1000197.

Dimeo, P. (2016). The myth of clean sport and its unintended consequences. Performance Enhancement \& Health, 4(3-4), 103-110. https://doi.org/10.1016/j. peh.2016.04.001

Dunn, M., Thomas, J. O., Swift, W., \& Burns, L. (2012). Elite athletes' estimates of the prevalence of illicit drug use: Evidence for the false consensus effect. Drug and Alcohol Review, 31(1), 27-32. https://doi.org/10.1111/ j.1465-3362.2011.00307.x

Elliot, D. L., Goldberg, L., Moe, E. L., DeFrancesco, C.A., Durham, M. B., \& Hix-Small, H. (2004). Preventing substance use and disordered eating: initial outcomes of the ATHENA (athletes targeting healthy exercise and nutrition alternatives) program. Archives of Pediatrics \& Adolescent Medicine, 158(11), 1043-1049. doi: 10.1001/ archpedi.158.11.1043

Elliot, D. L., Moe, E. L., Goldberg, L., DeFrancesco, C.A., Durham, M. B., \& Hix-Small, H. (2006). Definition and outcome of a curriculum to prevent disordered eating and body-shaping drug use. Journal of School Health, 76(2), 67-73. https://doi.org/10.1111/j.17461561.2006.00070.x

Erdman, K. A., Fung, T. S., Doyle-Baker, P. K., Verhoef, M. J., \& Reimer, R. A. (2007). Dietary supplementation of high-performance Canadian athletes by age and gender. Clinical Journal of Sport Medicine, 17(6), 458-464. doi: 10.1097/JSM.0b013e31815aed33

Fischetto, G., \& Bermon, S. (2013). From gene engineering to gene modulation and manipulation: Can we prevent or detect gene doping in sports? Sports Medicine, 43(10), 965-977. https://doi.org/10.1007/ s40279-013-0075-4

Fung, L., \& Yuan, Y. (2006). Performance enhancement drugs: knowledge, attitude, and intended behavior among community coaches in Hong Kong. The Sport Journal,
9(3), 1-5. Retrieved from https://thesportjournal.org/article/ performance-enhancement-drugs-knowledge-attitude-andintended-behavior-among-community-coaches-in-hongkong/

Goldberg, L., MacKinnon, D.P., Elliot, D., Moe, E., Clarke, G. \& Cheong, J. (2000) The adolescents training and learning to avoid steroids program: Preventing drug use and promoting health behaviors. Archives of Pediatric and Adolescent Medicine, 154(4), 332-338. doi: 10.1001/archpedi.154.4.332

Gonclaves, C., Coelho e Silva, M., Cruz, J., Torregrosa, M., \& Cumming, S. (2010). The effect of achievement goals on moral attitudes in young athletes. Journal of Sports Science and Medicine, 9(4), 605-611.

Goulet, C., Valois, P., Buist, A., \& Cote, M. (2010). Predictors of the use of performance-enhancing substances by young athletes. Clinical Journal of Sport Medicine, 20(4), 243-248. doi: 10.1097/JSM.0b013e3181e0b935

Gucciardi, D., Jalleh, G., \& Donovan, R.J. (2011). An examination of the sport drug control model with elite Australian athletes. Journal of Science \& Medicine in Sport, 14(6), 469-476. doi: 10.1016/j.jsams.2011.03.009.

Hallward, L., \& Duncan, L. R. (2019). A qualitative exploration of athletes' past experiences with doping prevention education. Journal of Applied Sport Psychology, 31(2), 187-202. https://doi.org/10.1080/10 413200.2018.1448017

Hanson, J. M. (2009) Equipping athletes to make informed decisions about perfor-mance-enhancing drug use: A constructivist perspective from educational psychology. Sport in Society, 12 (3), 394-410. https:// doi.org/10.1080/17430430802673734

Horcajo, J., Santos, D., Guyer, J. J. \& Moreno, L. (2019). Changing attitudes and intentions related to doping: An analysis of individual differences in need for cognition. Journal of Sports Sciences, 37(24), 2835-2843. https:// doi.org/10.1080/02640414.2019.1665876

Houlihan, B., Downward, P., Mayumi Yaya Yamamoto, M. Y., Rasciute, S., \& Takasu, K. (2020). Public opinion in Japan and the UK on issues of fairness and integrity in sport: Implications for anti-doping policy. International Journal of Sport Policy and Politics, 12(1), 1-24. https://doi.org/10.1080/19406940.2019.1615976

Houlihan, B., \& Melville, S. (2011). Improving and proving: A handbook for the evaluation of anti-doping education programmes. Canada: World Anti-Doping Agency.

Hurst, P., Kavussanu, M., Boardley, I., \& Ring, C. (2019). Sport supplement use predicts doping attitudes and likelihood via sport supplement beliefs. Journal of Sports Science, 37(15), 1734-1740. https://doi.org/10.1 080/02640414.2019.1589920

Johnson, M. B. (2012). A Systemic social-cognitive perspective on doping. Psychology of Sport and Exercise, 13, 317-323. https://doi.org/10.1016/j. psychsport.2011.12.007

Kavussanu, M., Ring, C., \& Hurst, P. (2018). The effects of moral disengagement on doping likelihood and guilt. 
In Division of Sport and Exercise Psychology Annual Conference, 2018.

Kavussanu, M., \& Ring, C. (2017). Moral identity predicts doping likelihood via moral disengagement and anticipated guilt. Journal of Sport \& Exercise Psychology, 39(4), 293-301. doi: 10.1123/jsep.20160333

Laure, P. \& Lecerf, T. (2002). Doping prevention among young athletes: Comparison of a health education-based intervention versus information-based intervention. Science \& Sports, 17(4), 198-201.

Laure, P. \& Lecerf, T. (1999). Prevention of doping in sport in adolescents: Evaluation of a health education based intervention. Archive Pediatrics, 6(8), 848-854.

Laure, P., Thouvenin, F., \& Lecerf, T. (2001). Attitudes of coaches towards doping. Journal of Sports Medicine and Physical Fitness, 41(1), 132-136.

Lazuras, L., Barkoukis, V., Rodafinos, A., \& Tzorbatzoudis, H. (2010). Predictors of doping intentions in elite-level athletes: A social cognition approach. Journal of Sport and Exercise Psychology, 32(5), 694 710. https://doi.org/10.1123/jsep.32.5.694

Lentillon-Kaestner, V., Hagger, M. S., \& Hardcastle, S. (2012). Health and doping in elite-level cycling. Scandinavian Journal of Medicine \& Science in Sports, 22(5), 596-606. https://doi.org/10.1111/j.16000838.2010.01281.x

Lucidi, F., Mallia, L., Alivernini, F., Chirico, A., Manganelli, S., Galli, F., ... \& Zelli, A. (2017). The effectiveness of a new school-based media literacy intervention on adolescents' doping attitudes and supplements use. Frontiers in Psychology, 8(74), 1-9. doi: 10.3389/fpsyg.2017.00749

Lucidi, F., Zelli, A., Mallia, L., Grano, C., Russo, P., \& Violani, C. (2008). The social-cognitive mechanisms regulating adolescents' use of doping substances. Journal of Sports Sciences, 26(5), 447-456. https://doi. org/10.1080/02640410701579370

Mazzeo, F., Monda, V., Santamaria, S., Nigro, E., Valenzano, A., Villano, I., ... \& Messina, G. (2018). Antidoping program: An important factor in the promotion and protection of the integrity of sport and athlete's health. The Journal of Sports Medicine and Physical Fitness, 58(7-8), 1135-1145. https://doi. org/10.23736/s0022-4707.17.07722-2

Melzer, M., Elbe, A. M., \& Brand, R. (2010). Moral and ethical decision-making: A chance for doping prevention in sports? Etikk $i$ praksis-Nordic Journal of Applied Ethics, 1, 69-85. https://doi.org/10.5324/eip.v4i1.1741

Morente-Sánchez, J., \& Zabala, M. (2013). Doping in sport: A review of elite athletes' attitudes, beliefs, and knowledge. Sports Medicine, 43(6), 395-411. https:// doi.org/10.1007/s40279-013-0037-x

Mottram, D., Chester, N., Atkinson, G., \& Goode, D. (2008). Athletes' knowledge and views on OTC medication. International Journal of Sports Medicine, 29(10), 851-855. doi: 10.1055/s-2008-1038403
Murofushi, Y., Kawata, Y., Kamimura, A., Hirosawa, M., \& Shibata, N. (2018). Impact of anti-doping education and doping control experience on anti-doping knowledge in Japanese university athletes: A cross-sectional study. Substance Abuse Treatment, Prevention, and Policy, 13(1), 44, 1-15. https://doi.org/10.1186/s13011-018-0178-x

Nicholls, A. R., Perrya J. L., Levy A. R., Meir, R., Jones, L., Baghurst, T., ... Thompson, M. A. (2015). Coach perceptions of performance enhancement in adolescence: The sport drug control model for adolescent athletes. Performance Enhancement \& Health, 3(2), 93101. doi: 10.1016/j.peh.2015.07.001.

Nieper, A. (2005). Nutritional supplement practices in UK junior national track and field athletes. British Journal of Sports Medicine, 39(9), 645-649. http:// dx.doi.org/10.1136/bjsm.2004.015842

Ntoumanis, N., Ng, J. Y., Barkoukis, V., \& Backhouse, S. (2014). Personal and psychosocial predictors of doping use in physical activity settings: A meta-analysis. Sports Medicine, 44(11), 1603-1624. doi: 10.1007/s40279014-0240-4

O’Donnell, T., Mazanov, J., \& Huybers, T. (2006). Towards a choice model of athletes' decision to use performance enhancing substances or methods: Factors and covariates. In ACSPRI Social Science Methodology Conference 2006, December 10-13, 2006, in Sydney, Australia.

Patterson, L. B., Backhouse, S. H., \& Duffy, P. J. (2016). Anti-doping education for coaches: qualitative insights from national and international sporting and anti-doping organisations. Sport Management Review, 19(1), 35-47. https://doi.org/10.1016/j.smr.2015.12.002

Patterson, L. B., Duffy, P. J., \& Backhouse, S. H. (2014). Are coaches anti-doping? Exploring issues of engagement with education and research. Substance Use \& Misuse, 49(9), 1182-1185. https://doi.org/10.3109/10 826084.2014.912469

Peretti-Watel, P., Pruvost, J., Guagliardo, V., Guibbert, L., Verger, P., \& Obadia, Y. (2005). Attitudes toward doping among young athletes in Provence. Science et Sports, 20(1), 33-40. http://dx.doi.org/10.1016/j. scispo.2004.04.003

Peters, C., Schulz, T., Oberhoffer, R., \& Michna, H. (2009). Doping and doping prevention: Knowledge, attitudes and expectations of athletes and coaches. Deutsche Zeitschrift Fur Sportmedizin, 60(3), 73-78.

Petróczi, A., Aidman, E. V., \& Nepusz, T. (2008). Capturing doping attitudes by self-report declarations and implicit assessment: A methodology study. Substance Abuse Treatment, Prevention, and Policy, 3(1), 1-9. doi: 10.1186/1747-597X-3-9

Petróczi, A., Norman, P., \& Brueckner, S. (2017). Can We Better Integrate the Role of Anti-Doping in Sports and Society? A Psychological Approach to Contemporary Value-Based Prevention. Acute Topics in Anti-Doping, 62, 160-176. https://doi.org/10.1159/000460726

Ring, C., Kavussanu, M., \& Gürpınar, B. (2020). Basic values predict doping likelihood. Journal of Sports 
Science, 38(4), 357-365. https://doi.org/10.1080/02640 414.2019.1700669

Ring, C., \& Kavussanu, M. (2018). The impact of achievement goals on cheating in sport. Psychology of Sport and Exercise, 35, 98-103. doi: 10.1016/j. psychsport.2017.11.016.

Sagoe, D., Holden, G., Rise, E. N. K., Torgersen, T., Paulsen, G., Krosshaug, T., ... \& Pallesen, S. (2016). Doping prevention through anti-doping education and practical strength training: The Hercules program. Performance Enhancement \& Health, 5(1), 24-30. https://doi.org/10.1016/j.peh.2016.01.001

Smith, A., Stewart, B., Oliver-Bennetts, S., McDonald, S., Ingerson, L., Anderson, A., Dickson, G., Emery, P., \& Graetz, F. (2010). Contextual influences and athlete attitudes to drugs in sport. Sport Management Review, 13, 181-197. https://doi.org/10.1016/j.smr.2010.01.008

Steinfeldt, J., Rutkowski, L., Vaughan, E., \& Steinfeldt, M. (2011). Masculinity, moral atmosphere and moral functioning of high school football players. Journal of Sport \& Exercise Psychology, 33(2), 215-234. doi: https:// doi.org/10.1123/jsep.33.2.215

Striegel, H., Ulrich, R., \& Simon, P. (2010). Randomized response estimates for doping and illicit drug use in elite athletes. Drug and Alcohol Dependence, 106(2-3), 230232. https://doi.org/10.1016/j.drugalcdep.2009.07.026

Striegel, H., Vollkommer, G., \& Dickhuth, H. H. (2002). Comnbating drug use in competitive sports. Journal of Sports Medicine and Physical Fitness, 42(3), 354.

Triviño, J. L. P. (2011). Gene doping and the ethics of sport: Between enhancement and posthumanism. International Journal of Sports Science, 1(1), 1-8. doi: 10.5923/j.sports.20110101.01

Vorstenbosch., J. (2010). Doping and Cheating. Journal of the Philosophy of Sport, 37, 166-181. https://doi.org/ 10.1080/00948705.2010.9714774

Wippert, P. A., \& Fließer, M. (2016). National doping prevention guidelines: Intent, efficacy and lessons learned-A 4-year evaluation. Substance Abuse Treatment, Prevention, and Policy, 11(35), 42. doi: 10.1186/s13011016-0079-9

World Anti-Doping Agency. (2015). ADO reference guide. Retrieved from https://www.wada-ama.org/en/ resources/education-and-prevention/athlete-referenceguide-to-2015-code-online-version

World Anti-Doping Agency. (2015). World Anti-Doping Code. Retrieved from https://www.wada-ama.org/sites/ default/files/resources/files/wada-2015-world-antidoping-code.pdf 